\title{
Increased ERp57 Expression in HBV-Related Hepatocellular Carcinoma: Possible Correlation and Prognosis
}

\author{
Miao Liu, ${ }^{1,2}$ Lingyao Du, ${ }^{1,2}$ Zhiliang He, ${ }^{1,2}$ Libo Yan, ${ }^{1,2}$ Ying Shi, \\ Jin Shang, ${ }^{1,2}$ and Hong Tang ${ }^{1,2}$ \\ ${ }^{1}$ Center of Infectious Diseases, West China Hospital, Sichuan University, Chengdu 610041, China \\ ${ }^{2}$ Division of Infectious Diseases, State Key Laboratory of Biotherapy and Cancer Center, West China Hospital, \\ Sichuan University and Collaborative Innovation Center for Biotherapy, Chengdu 610041, China \\ Correspondence should be addressed to Hong Tang; htang6198@hotmail.com
}

Received 20 December 2016; Accepted 13 February 2017; Published 8 March 2017

Academic Editor: Shanhong Tang

Copyright (C) 2017 Miao Liu et al. This is an open access article distributed under the Creative Commons Attribution License, which permits unrestricted use, distribution, and reproduction in any medium, provided the original work is properly cited.

\begin{abstract}
Aim. ERp57 is involved in virus induced endoplasmic reticulum stress (ERS) and plays an important role in tumorigenesis This study aimed to find whether HBV infection altered ERp57 expression and whether ERp57 regulation was involved in hepatitis B virus-related hepatocellular carcinoma (HBV-HCC) genesis. Materials and Methods. HBV-HCC tissues, chronic hepatitis B (CHB) liver tissues, and normal liver tissues were acquired. ERp57 expressions in these tissues were detected through immunohistochemistry (IHC). And ERp57 expression in liver cell line L02, HBV replicative liver cell line L02-pHBV4.1, and HCC cell lines were detected through western blot for verification. Then medical data on patients providing HCC tissues were collected and analyzed along with ERp57 expression. Results. Higher ERp57 expression was found in HCC and CHB tissues $(p<0.001)$. And HCC cell lines and L02-pHBV4.1 presented higher ERp57 expression as well. In patients, ERp57 expression showed significant differences between death and survival groups $(p=0.037)$. And cumulative survival in patients with higher ERp57 (score $\geqslant 8.75)$ is significantly lower $(p=0.009)$. Conclusion. Our study found increased expression of ERp57 in HBV-HCC. Such altered expression could be related to HBV infection and high ERp57 expression may lead to poor prognosis of HBV-HCC patients.
\end{abstract}

\section{Background}

Hepatitis B virus (HBV) infection is one of the leading causes of hepatocellular carcinoma [1]. Although its mechanisms has been studied for decades, there is still a lot of information that remains unknown. Recent studies have confirmed that some host factors interacting with $\mathrm{HBV}$ were involved in viral tumorigenesis, resulting in alternation of host cell biological characteristics [2-4]. The endoplasmic reticulum (ER), where viral DNA replicates and viral proteins are synthesized, could be easily influenced by virus. When virus infects cells, plenty of unfolding or misfolding proteins aggregates in ER to generate a stress. Series of procedures, called endoplasmic reticulum stress (ERS) response, would be triggered to ease it afterwards. And overresponse of ERS would trigger overtranscription of target genes downstream including oncogenes. Endoplasmic reticulum proteins (ERps) play critical roles in ERS and many proteins such as ERp29, ERp72, and calreticulin identified to be ERS concerning [5-8].

In 1999, Oliver found that ERp57 could interact with calreticulin, influencing the folding of newly synthesized proteins [9]. As an important protein disulfide isomerase (PDI), ERp57/GRP58 has been named after abbreviation of endoplasmic reticulum resident protein 57 or $58 \mathrm{kDa}$ glucoseregulated protein. It catalyzes formation, decomposition, and isomerization of disulfide bond, working as a multifunctional protein in kinds of biological procedures [10]. In tumorigenesis, ERp57 presents contradictory roles among different tumors. Low expression of ERp57 in gastric cancer patients would lead to poor prognosis [11]. However, high expression in ovarian cancer patients would result in drug resistance and lead to poor prognosis as well [12]. In liver diseases, ERp57 is suggested to be involved in several hepatic disorders. 
TABLE 1: Detailed criteria of Axiotis Score*.

\begin{tabular}{cccc}
\hline & Percentage score & \multicolumn{2}{c}{ Intensity score } \\
\hline 0 & $0 \sim 10 \%$ positive cells & 0 & No color \\
1 & $11 \sim 25 \%$ positive cells & 1 & Yellow \\
2 & $26 \sim 50 \%$ positive cells & 2 & Brown \\
3 & $51 \sim 75 \%$ positive cells & 3 & Tan \\
4 & $76 \sim 100 \%$ positive cells & & \\
\hline
\end{tabular}

${ }^{*}$ The sum of the two scores equaled the sum score. And five different sum scores from random view under 400x magnification were acquired for a mean sum score. The assessments were implemented by two pathologists unaware of the tissue section arrangement. If there were differences in their opinions, extra mean would be calculated with the two mean sums for final score.

However, there is no specific study focusing on its roles in HBV-related hepatocarcinogenesis.

So we conducted this study, trying to clarify whether HBV infection altered ERp57 expression and whether ERp57 regulation was involved in hepatitis B virus-related hepatocellular carcinoma (HBV-HCC) genesis.

\section{Methods}

2.1. Study Subjects. Tissue sections of HBV-HCC were obtained from pathologic specimen bank of West China Hospital, Sichuan University. Each set of tissues contained a cancer tissue section, an adjacent one and a distal one. Patients providing these samples were part of pathologically diagnosed HBV-HCC patients in West China Hospital in 2012. Their medical data were collected via electronic medical system. Their prognosis was acquired via telephone follow-up.

The chronic hepatitis B (CHB) liver sections were acquired from $\mathrm{CHB}$ patients consulting in West China Hospital when liver biopsy was needed to make therapeutic decision. Normal liver sections were acquired from the specimen bank in Department of Forensic Pathology, West China School of Basic and Forensic Medicine, Sichuan University.

HCC cell lines including Huh7, HepG2, and HepG2.2.15, HBV replicative normal liver cell line L02-pHBV4.1, and normal liver cell line L02 were stored in Division of Infectious Diseases, State Key Laboratory of Biotherapy and Cancer Center.

\subsection{Study Method}

2.2.1. Detection of ERp57 Expression in Tissue Samples. Immunohistochemistry (IHC) was used to detect ERp57 expression in tissues. The primary antibody was a rabbit polyclonal IgG to ERp57 (sc-28823, Santa Cruz, USA). And the secondary antibody was part of EnVision ${ }^{\mathrm{TM}}$ G2 Systems (Dako, Glostrup, Denmark). With 3,3- diaminobenzidine as reagent to horseradish peroxidase (HRP) linked to the secondary antibody, ERp57 were stained. Nucleus was counterstained with hematoxylin then. After mounting, tissue sections were scored according to Axiotis standard. The percentage of positive cells and its staining intensity were evaluated. The detailed scoring criteria were in Table 1 .
TABLE 2: Sequences of primers used in RT-PCR.

\begin{tabular}{ll}
\hline Primer name & Sequence \\
\hline $\begin{array}{l}\text { ERp57 forward } \\
\text { primer }\end{array}$ & $5^{\prime}$-CTCCTCGCCTCCGCCTCAGA-3' \\
ERP57 reverse primer & $5^{\prime}$-AGCCCACCACCGAGGCATCT-3' \\
$\begin{array}{l}\text { GAPDH forward } \\
\text { primer }\end{array}$ & $5^{\prime}$-ACCCACTCCTCCACCTTTGA-3' \\
$\begin{array}{l}\text { GAPDH reverse } \\
\text { primer }\end{array}$ & $5^{\prime}$-CTGTTGCTGTAGCCAAATTCGT-3' \\
\hline
\end{tabular}

2.2.2. Detection of ERp57 Transcription and Expression in Cells. Total RNA was extracted from cells with Trizol (ThermoFisher, USA) and reversely transcribed into cDNA. RTPCR was applied to detect ERp57 transcription with Fast Start Universal SYBR Green Master in light Cycler 96 (Roche). Detailed information of primers used in RT-PCR was shown in Table 2.

Cells were lysed for total proteins. After quantitation, total proteins were separated with electrophoresis in SDSpolyacrylamide gel and transferred to PVDF membrane. With same multifunctional primary antibody as before and HRP-linked goat against rabbit secondary antibody (ZSGBBIO, Beijing, China), ERp57 were marked and visualized via chemiluminescent substrate (ThermoFisher, USA) and ChemiDoc $^{\mathrm{TM}}$ MP imaging system (Bio-Rad, USA). Then band intensity of ERp57 expression was semiquantified in the imaging system.

2.3. Statistical Analysis. All data were processed and analyzed in SPSS 18.00. Enumeration data were described with percentage and analyzed with chi-square test. Measurement data were analyzed for normality first. If the data was normal, it would be described with mean and standard deviation (SD), analyzed with $t$-test. Otherwise it would be described with median and interquartile range (IQR), analyzed with $u$ test. Relationship between associated factors, ERp57 expression, and prognosis were analyzed with correlation or regression. The prognosis was analyzed with cumulative survival with Mantel-Cox test.

2.4. Ethics Approval and Consent to Participate. The biological samples were acquired for medical or forensic purpose other than our study originally. Samples of HCC tissues were acquired according to surgical resection of tumors. And samples from $\mathrm{CHB}$ patients were originally used for assessment of antiviral indications. Normal tissues were originally prepared for medicolegal expertise. Informed consent was signed by patients or their relatives when these actions happened and additional editions were acquired at the same time for samples' further usage of investigational purpose. When follow-up phone calls were made to patients or their relatives, oral permissions on their tissue sections and medical data to be applied in this study were acquired as well. All the procedures were approved and supervised by Ethics Committee of West China Hospital, Sichuan University. 


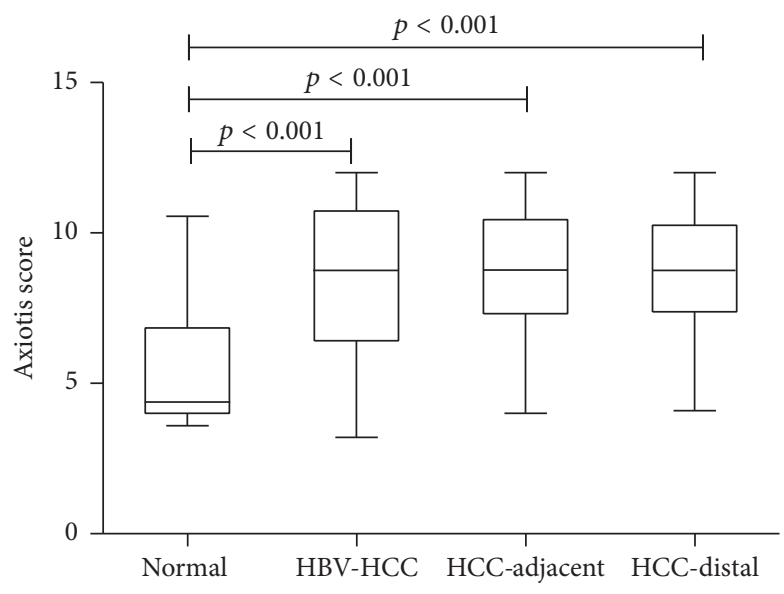

(a)
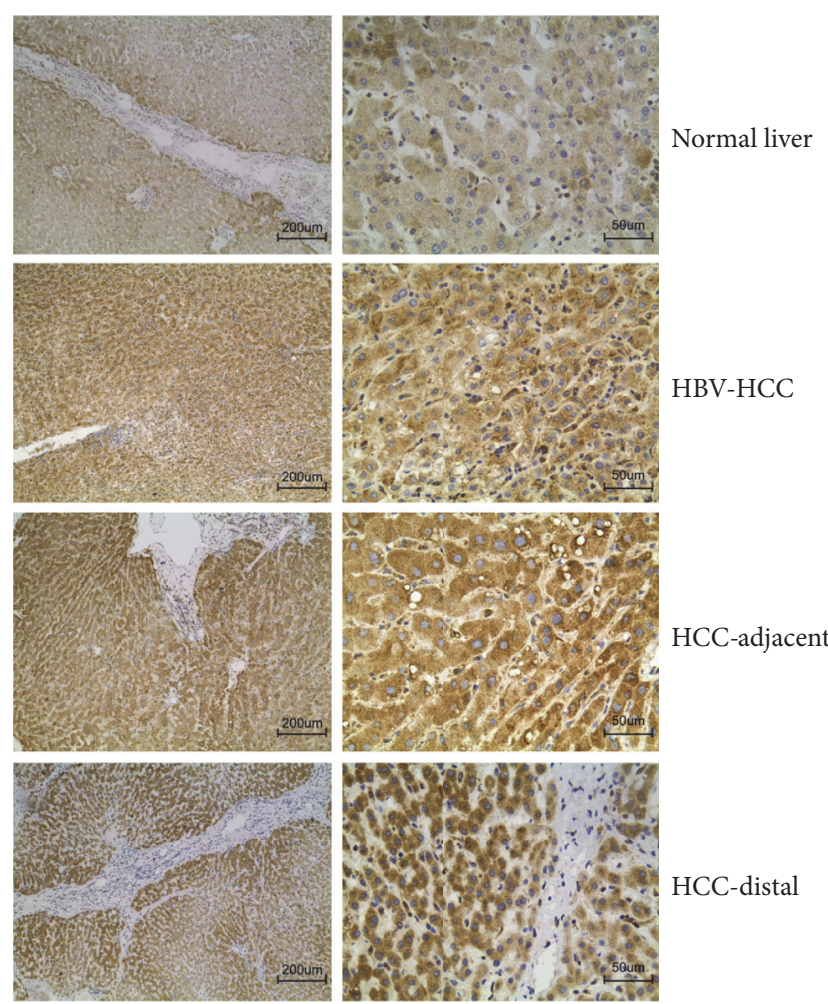

(b)

FiguRE 1: ERp57 expression in HCC liver tissues. (a) Statistical diagram of ERp57 expression score in normal livers and HCC tissues. (b) Representative images of IHC stained ERp57 in normal livers and HCC tissues.

\section{Results}

3.1. ERp57 Expression in Different Kinds of Liver Tissues. A total of 66 sets of HBV-HCC tissues, 57 CHB tissues, and 16 normal liver tissues were acquired in this study. And positive ERp57 expression was found in all kinds of tissues through IHC. Though no significant difference was found between the median Axiotis score of cancer tissues, adjacent tissues and distal tissues $(10.725 \pm 2.325$ versus $10.45 \pm 1.45$ versus 10.25 \pm 1.36 ), respectively, their ERp57 expression was significantly higher compared to normal liver tissues $(4.375 \pm 2.84)$ (Figure 1). Thus ERp57 expression was altered not only in HBVHCC tissues but also in HBV-HCC related adjacent and distal tissues. It suggested that the alternation of ERp57 expression could be related to cellular malignant transformation.

However, the distal tissues showed little manifestation of tumor cells but a status of HBV infection, so HBV infection might be another impact factor to ERp57 expression. To clarify this, $\mathrm{CHB}$ liver tissues were compared with normal ones. Its median Axiotis score of ERp57 expression was significantly increased compared to normal liver tissues $(4.375 \pm 2.84$ versus $5.8 \pm 4.025, p<0.001)$ (Figure 2). Such result suggested that HBV infection could be another promoting factor of high ERp57 expression.

3.2. ERp57 Expression in Different Kinds of Liver Cell Lines. Experimental results in cell lines confirmed the correlation between cellular malignant transformation, $\mathrm{HBV}$ infection, and ERp57 expression. ERp57 expression in HCC cell lines including Huh7, HepG2, and HepG2.2.15 was significantly increased compared to normal liver cell L02, proving that cellular malignant transformation promoted ERp57 expression. As preconceived, the ERp57 expression in Huh7 and HepG2 was only increased moderately. But it was increased strongly in HepG2.2.15 cells which mimicked a status of HBV-HCC (Figure 3).

L02-pHBV4.1 was established by stably transfecting HBV replicative plasmid pHBV4.1 into L02. It mimicked the status of HBV infected liver without inflammatory cell infiltration and it is applicable to investigate the influence from $\mathrm{HBV}$ to host cytokines. In this cell, ERp57 transcription and expression were significantly increased compared to L02, suggesting that HBV did promote ERp57 expression and such influence could be relevant to ERp57 transcription (Figure 4).

3.3. Correlation between ERp57 Expression in HBV-HCC Tissues and Prognosis. In the $66 \mathrm{HBV}-\mathrm{HCC}$ patients providing tissues, male patients took the minority $(N=8)$. The mean age was $50.23 \pm 11.60$ years old. Alpha fetal protein (AFP) in these patients was distributed widely $(0.92-495383.00 \mathrm{ng} / \mathrm{ml})$. Most patients only showed moderately elevated ALT (47 \pm $38.5 \mathrm{IU} / \mathrm{L})$. Most patients $(N=52)$ were diagnosed as $\mathrm{HBeAg}$ negative $\mathrm{CHB}$. Viral loads of the whole crowed located at a relatively low level $(500 \pm 6167.5 \mathrm{IU} / \mathrm{mL})$. According to radiological examinations, surgery records, and pathological reports, Ishake score of the 66 distal tissues showed a median 


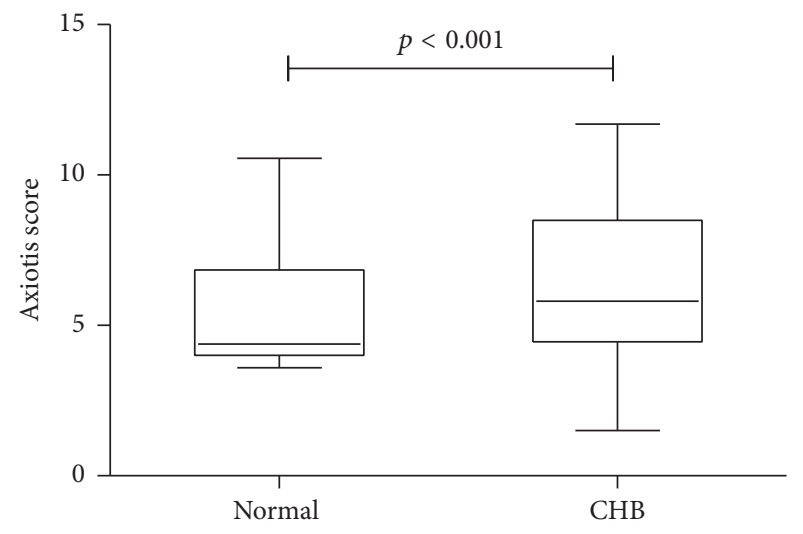

(a)
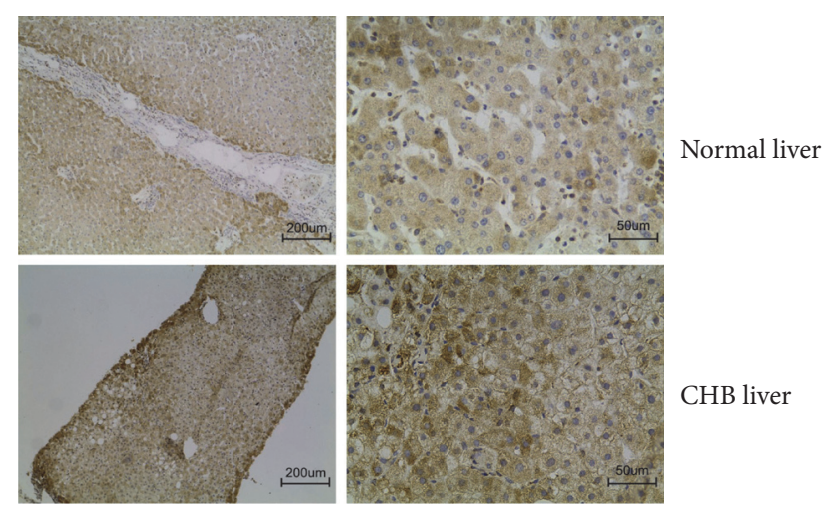

(b)

FIGURE 2: ERp57 expression variation in CHB liver tissues. (a) Statistical diagram of ERp57 expression score in normal livers and CHB liver tissues. (b) Representative images of IHC stained ERp57 in normal livers and CHB liver tissues.

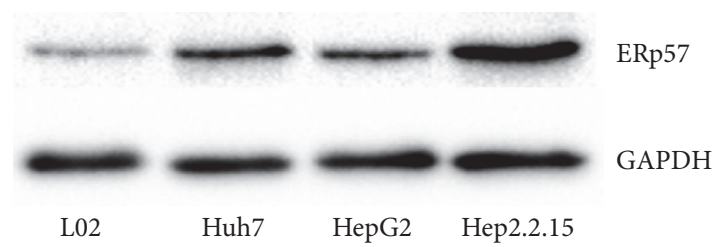

(a)

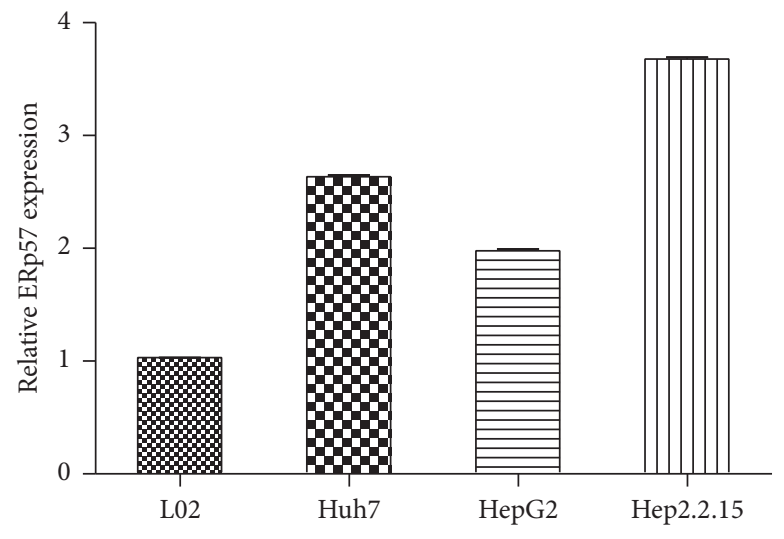

(b)

FIGURE 3: ERp57 expression in normal liver cell line and HCC cell lines. (a) ERp57 expression detected by western blot in different cell lines with GAPDH as internal reference. (b) Statistical diagram of Quantity One captured western blot detected ERp57 expression data. The ERp57/GAPDH ratios of other cell lines were transformed into relative ratio according to the ERp57/GAPDH ratio of L02 cells as "1."

value of $5 \pm 2$, implying most patients had background of cirrhosis. And 46 patients suffered tumors with size $\geqslant 5 \mathrm{~cm}$. Moreover, high differentiated tumor was found in 6 patients, while moderate differentiation was found in 50 patients and poor differentiation was found in 10 patients. Capsule invasion, margin involvement, tumor thrombus, and metastasis were found in 39, 3, 21, and 7 patients, respectively. Till the date of follow-up call made (December, 2015), 28 patients survived and 19 patients died of HCC related complications. The other 19 patients were lost to follow-up (Table 3).

Patients' biological characteristics and factors related to the disease status were analyzed for their correlation to ERp57 expression in cancer tissues. Through univariate analysis, occurrence of tumor thrombus and prognosis were identified as two significant factors related to ERp57 expression in cancer tissues in this crowd ( $p=0.021$ and 0.037) (Table 3). As patients with tumor thrombus would encounter poor prognosis more frequently, the significant relationship between ERp57 expression and tumor thrombus also reminded that ERp57 was an essential factor related to prognosis.
So we excluded patients lost to follow-up, dividing the rest of them into two groups according to their prognosis (death or survival). The occurrence of tumor thrombus was obviously more frequent in patients with poor prognosis $(p=$ 0.003 ) and ERp57 expression did show significant differences between the death and survival groups $(10.6+4.15$ versus $8.025+3.4, p=0.037$ ) (Table 4). Then we calculated an ROC curve to identified a cut-off value (Axiotis score $=$ 8.75) and divided whole crowd into two groups according to the criterion. In the follow-up period of 36 months, the cumulative survival in group with score $\geqslant 8.75$ is significantly lower compared to group with score $<8.75(p=0.009)$ (Figure 5). All these results suggested that HBV-HCC patients with higher expression of ERp57 in cancer tissues would encounter shorter life expectancy.

\section{Discussion}

The solid tumor cells live in an acid environment with low oxygen because tumor itself usually develops faster 


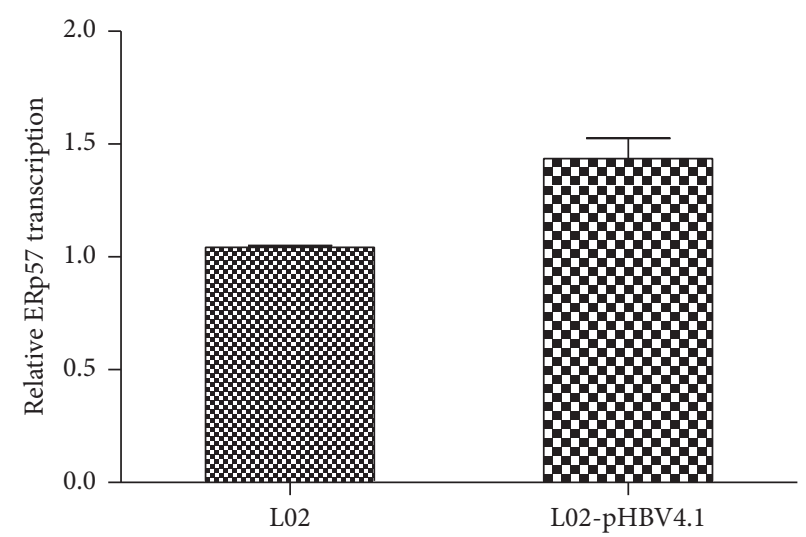

(a)

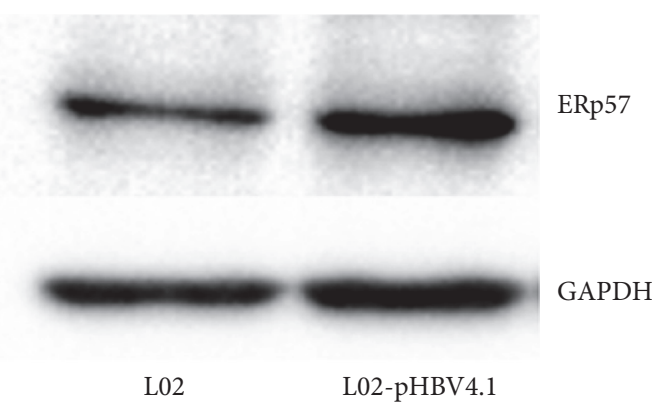

(b)

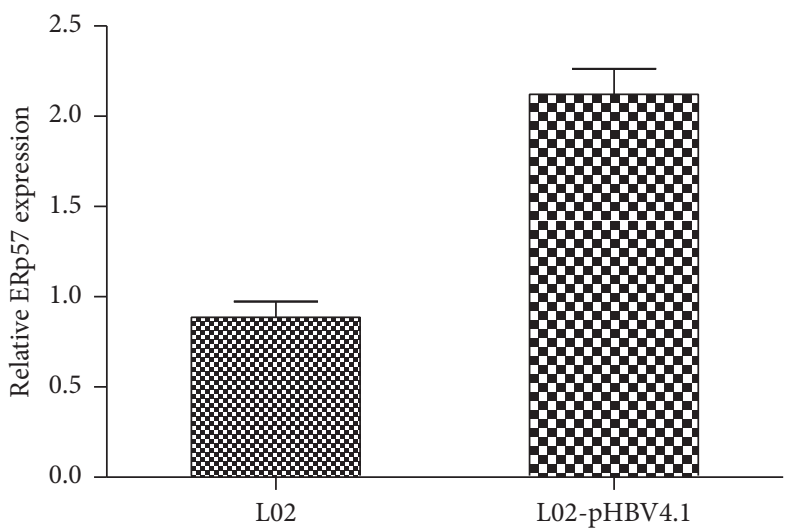

(c)

FIGURE 4: Transcription and expression level of ERp57 in normal liver cell line L02 and HBV replicative liver cell line L02-pHBV4.1. (a) RT-PCR detected relative ERp57 mRNA level in L02 and L02-pHBV4.1 with GAPDH as internal reference. (b) ERp57 expression detected by western blot in L02 and L02-pHBV4.1 with GAPDH as internal reference. (c) Statistical diagram of Quantity One captured western blot detected ERp57 expression data. The ERp57/GAPDH ratios of HBV infected cell line, L02-pHBV4.1, was transformed into relative ratio according to the ERp57/GAPDH ratio of L02 cells as "1."

TABLE 3: Univariate analysis of factors related to ERp57 expression in HCC tissue sections.

\begin{tabular}{|c|c|c|c|}
\hline Factors & $\begin{array}{c}\text { Frequency/media (mean) } \pm \\
\mathrm{IQR}(\mathrm{SD})\end{array}$ & $\begin{array}{l}\text { Mann-Whitney test }(Z) / \text { Pearson } \\
\text { test }(r) / \text { Kruskal-Wallis test }\left(X^{2}\right)\end{array}$ & $P$ value \\
\hline Gender (male/female) & $8 / 58$ & -0.079 & 0.937 \\
\hline Age (year) & $50.23 \pm 11.60$ & -0.169 & 0.176 \\
\hline $\operatorname{AFP}(\mathrm{ng} / \mathrm{ml})$ & $198.3 \pm 1690.84$ & 0.213 & 0.091 \\
\hline ALT (IU/L) & $47 \pm 38.5$ & -0.105 & 0.408 \\
\hline HBeAg (positive/negative) & $14 / 52$ & -1.044 & 0.297 \\
\hline HBVDNA (IU/mL) & $500 \pm 6167.5$ & 0.089 & 0.480 \\
\hline Ishak Score & $5 \pm 2$ & -0.210 & 0.090 \\
\hline Tumor Size $(<5 \mathrm{~cm} / \geqslant 5 \mathrm{~cm})$ & $20 / 46$ & -1.487 & 0.137 \\
\hline $\begin{array}{l}\text { Differentiated degree } \\
\text { (poor/moderate/high) }\end{array}$ & $10 / 50 / 6$ & -1.347 & 0.178 \\
\hline Capsule invasion (positive/negative) & $39 / 27$ & -1.742 & 0.081 \\
\hline $\begin{array}{l}\text { Margin involvement } \\
\text { (positive/negative) }\end{array}$ & $3 / 63$ & -0.893 & 0.372 \\
\hline Tumor thrombus (positive/negative) & $21 / 45$ & -2.3 & 0.021 \\
\hline Metastasis (positive/negative ) & $7 / 59$ & -1.063 & 0.288 \\
\hline $\begin{array}{l}\text { Prognosis (death/survival/lost to } \\
\text { follow-up) }\end{array}$ & $19 / 28 / 19$ & -2.083 & 0.037 \\
\hline
\end{tabular}


TABLE 4: Univariate analysis of factors related to prognosis in patients within follow-up $(N=47)$.

\begin{tabular}{|c|c|c|c|c|}
\hline Factors & $\begin{array}{c}\text { Death } \\
(N=19)\end{array}$ & $\begin{array}{l}\text { Survival } \\
(N=28)\end{array}$ & $\begin{array}{c}\text { Mann-Whitney test } \\
(Z) / \text { Pearson test } \\
(r) / \text { Kruskal-Wallis test }\left(X^{2}\right)\end{array}$ & $P$ value \\
\hline Gender (male/female) & $17 / 2$ & $25 / 3$ & -0.000 & 1.000 \\
\hline Age (year) & $46 \pm 25$ & $50.5 \pm 13.75$ & -0.651 & 0.515 \\
\hline $\operatorname{AFP}(\mathrm{ng} / \mathrm{ml})$ & $528.8 \pm 3064.72$ & $93.62 \pm 1153.70$ & -0.902 & 0.367 \\
\hline ALT (IU/L) & $37 \pm 23.5$ & $46 \pm 28$ & -1.206 & 0.228 \\
\hline HBeAg (positive/negative) & $2 / 17$ & $8 / 20$ & 2.201 & 0.168 \\
\hline HBVDNA (IU/mL) & $500 \pm 0$ & $500 \pm 10775$ & -1.192 & 0.233 \\
\hline Ishak Score & $4 \pm 2$ & $5 \pm 2$ & -0.906 & 0.365 \\
\hline Tumor Size $(<5 \mathrm{~cm} / \geqslant 5 \mathrm{~cm})$ & $5 / 14$ & $11 / 17$ & 0.848 & 0.357 \\
\hline $\begin{array}{l}\text { Differentiated degree } \\
\text { (poor/moderate/high) }\end{array}$ & $3 / 16 / 0$ & $3 / 20 / 5$ & 3.863 & 0.145 \\
\hline $\begin{array}{l}\text { Capsule invasion } \\
\text { (positive/negative) }\end{array}$ & $9 / 10$ & $15 / 13$ & 0.174 & 0.676 \\
\hline $\begin{array}{l}\text { Margin involvement } \\
\text { (positive/negative) }\end{array}$ & $2 / 17$ & $1 / 27$ & 0.916 & 0.338 \\
\hline $\begin{array}{l}\text { Tumor thrombus } \\
\text { (positive/negative) }\end{array}$ & $10 / 9$ & $3 / 25$ & 9.940 & 0.003 \\
\hline $\begin{array}{l}\text { Metastasis } \\
\text { (positive/negative) }\end{array}$ & $3 / 16$ & $1 / 27$ & 2.170 & 0.289 \\
\hline $\begin{array}{l}\text { Axiotis score of ERp57 } \\
\text { expression in tissue } \\
\text { sections }\end{array}$ & $10.6 \pm 4.15$ & $8.025 \pm 3.4$ & -2.083 & 0.037 \\
\hline
\end{tabular}

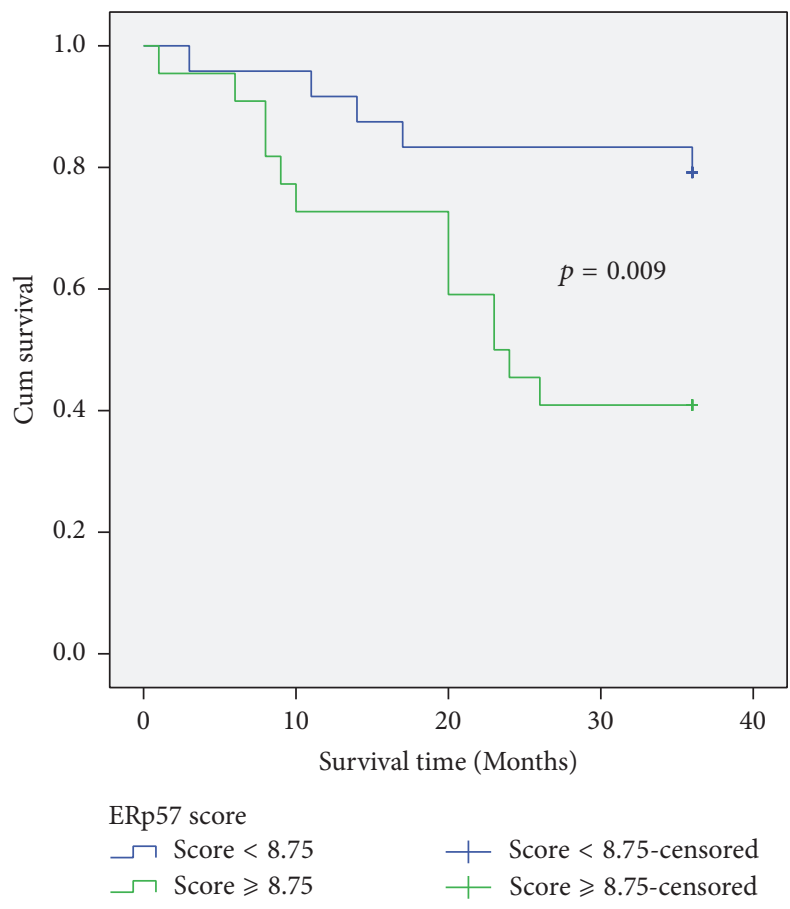

Figure 5: Cumulative Survival in two groups divided by ERp57 expression. Two groups were divided by cut-off value (Axiotis score $=8.75$ ). Blue curve represented the group with ERp57 score < 8.75, while the green curve represented the group with ERp57 score $\geqslant$ 8.75. According to Mantel-Cox test, cumulative survival of these two groups showed significant difference $(p=0.009)$. than its vascularization [5]. In such an environment, ERS is essential to tumor cells. It activates series of signaling transduction pathway to assist the cell adaptive survival. For example, ERp57 in cells works coordinately with calreticulin to influence folding of newly synthesized proteins. Upregulated ERp57 would induce unfolded protein response (UPR), one type of ERS, to prevent export of unfolded proteins. Through such way, tumor cells could maintain their cellular homeostasis for survival [6, 7]. And when ERp57 joins in transcriptional complex assembly along with STAT3, it could be involved in nuclear signaling pathway to promote cell proliferation. However, ERp57 also participates in formation of major histocompatibility complex class I (MHC I) to influence the immunogenicity of tumor cells. So upregulated ERp57 would accelerate maturation of dendritic cells, enhancing host surveillance and reducing production of negative regulators to antitumor immunity [13].

The controversial function in the mechanism endows ERp57 complicated roles in different kinds of tumors [11, 12, 14]. However, the exact role it played in HBV-HCC remained to be learned. In our study, we found that no matter in HBVHCC cancer tissues, adjacent tissues, or distal tissues, higher expression of ERp57 was found compared to normal liver tissue. Interestingly, ERp57 expression among the three kinds of HBV-HCC related tissues showed no differences. Such result implied that ERp57 was increased in cell transition to malignancy. And its expression might have been upregulated already before the cells were fully transformed. The fact that cell lines derived from HCC presented higher ERp57 
expression than normal liver cells also verified the correlation between malignant transition and ERp57 expression.

The background of HBV infection no matter in HBVHCC tissues, especially the distal ones, or in HepG2.2.15 cells suggested a possible correlation between HBV infection and ERp57 expression. HBV has been confirmed as a tumorigenesis virus for decades [15]. As the endoplasmic reticulum is an important site of virus replication and progeny virus assembly, plenty of viral proteins aggregate in the ER when virus infected ER, triggering ERS to upregulated ER proteins expression [16]. Previous study has found HCV could upregulate ER proteins such as GRp78 and GRp94 in the liver [17]. As another hepatotropic virus, HBV was confirmed to be involved in the regulation of ER proteins in our study. ERp57 expression was increased both in liver tissues and in cell lines if there was HBV infection.

It was interesting that when we analyzed the relationship between serum HBV viral load and the ERp57 expression in HCC patients, no significant result was found ( $p=0.480)$. Such phenomenon seemed not to make sense as HBV was considered to be one of the ERp57 inducers. However, the extremely low level of viremia in HCC patients would be an explanation. Viruses need proper intracellular environment to accomplish their life cycles. As a result, the alternation in HCC cells as well as the host immunity of HCC patients would inhibit the viral replication [18]. In our study, the median viral load is $2 \log 10 \mathrm{IU} / \mathrm{mL}$. Statistically, extremely low serum HBV DNA would decrease the difference of serum viral load among patients and lead to an insufficient analysis. Moreover, the cells had been malignantly transformed already. As we found that HCC cell lines presented higher expression of ERp57 (Figure 3), the impact from HBV to ERp57 expression would be covered by the malignant transformation to some degree. In recent studies, scientists proved again that the serum HBV DNA and intracellular cccDNA and total DNA were significantly higher in $\mathrm{CHB}$ patients than in HCC patients, and they also found an inconsistency between serum viral DNA and intracellular viral DNA in HCC patients [19]. So significant relationship might be found if intracellular HBV DNA could be detected other than serum HBV DNA.

ERp57 expression was reported to be associated with prognosis of patients. In gastric cancer where ERp57 presented as a tumor inhibitor, low expression of ERp57 results in poor prognosis [11]. However, the situation was quite different in our study. When possible factors related to ERp57 expression were analyzed, the existence of tumor thrombus and prognosis were the only two significant ones. Portal vein tumor thrombus in HCC is a proved poor prognostic factor [20]. Patients with portal vein tumor thrombus were reported to encounter a median survival time about 4 months [21, 22]. So the result suggested a correlation between high ERp57 expression and poor prognosis. Moreover, when patients were grouped according to their prognosis, ERp57 was increased significantly in the death group. And the cumulative survival analysis revealed that patients with higher ERp57 expression would have shorter survival time. These results proved that ERp57 was involved in the prognosis of HBVHCC patients and its influence on the occurrence of tumor thrombus could be one way. Other studies supported our findings. A newly reported research demonstrated that Antrodia cinnamomea (EEAC), a Chinese herb, decreased ERp57 to suppress HCC migration. Downregulation of ERp57 by siRNA effectively inhibit transwell immigration of HCC cells. It suggested that ERp57 could affect cell proliferation and migration [23].

ERp57 locates in cytoplasm, nucleus, and endoplasmic reticulum. Its dynamic subcellular localization is considered as a key factor to explain its complex action in tumorigenesis. Oncogene activation is vastly related to ERp57 immigration into nucleus as part of transcription complex. As part of STAT-3 transcription complex, ERp57 translocated into nucleus to modulate intracellular gene expression mediated by TORC1 and TORC2, interfering Ref-A1 related DNA repair [24, 25]. And ERp57 also combines with nuclear factor $\kappa \mathrm{B}(\mathrm{NF}-\kappa \mathrm{B})$, altering its subcellular location [13]. So the correlation between dynamic subcellular localization of ERp57 and its multiple biological function is worth further investigation.

\section{Conclusion}

Our study found increased expression of ERp57 in HBVHCC. Such altered expression could be related to HBV infection and high ERp57 expression may lead to poor prognosis of HBV-HCC patients. It provides information on the role ERp57 played in HBV-HCC genesis, guiding us a direction to further investigations in its mechanism.

\section{Competing Interests}

There are no competing interests in the article and no permission needs to be acquired for its publication.

\section{Authors' Contributions}

Miao Liu and Lingyao Du contributed equally to the manuscript.

\section{Acknowledgments}

This work was supported by "973” National Basic Research Program of China (2013CB911302) and Science and Technology Projects of Sichuan Province (2015SZ0049). Basic experiment of this study was supported by Fund 2013CB911302 and clinical follow-up of HCC patients was supported by Fund 2015 SZ0049.

\section{References}

[1] Y. Huang and A. S. F. Lok, "Viral factors and outcomes of chronic HBV infection," American Journal of Gastroenterology, vol. 106, no. 1, pp. 93-95, 2011.

[2] X. Tian, J. Li, Z.-M. Ma, C. Zhao, D.-F. Wan, and Y.-M. Wen, "Role of hepatitis B surface antigen in the development of hepatocellular carcinoma: regulation of lymphoid enhancerbinding factor 1," Journal of Experimental and Clinical Cancer Research, vol. 28, no. 1, article 58, 2009. 
[3] E. Hildt, B. Munz, G. Saher, K. Reifenberg, and P. H. Hofschneider, "The PreS2 activator $\mathrm{MHBs}^{t}$ of hepatitis B virus activates c-raf-1/Erk2 signaling in transgenic mice," EMBO Journal, vol. 21, no. 4, pp. 525-535, 2002.

[4] Y.-W. Li, F.-C. Yang, H.-Q. Lu, and J.-S. Zhang, "Hepatocellular carcinoma and hepatitis B surface protein," World Journal of Gastroenterology, vol. 22, no. 6, pp. 1943-1952, 2016.

[5] C. Giampietri, S. Petrungaro, S. Conti, A. Facchiano, A. Filippini, and E. Ziparo, "Cancer microenvironment and endoplasmic reticulum stress response," Mediators of Inflammation, vol. 2015, Article ID 417281, 11 pages, 2015.

[6] S. Taouji and É. Chevet, "Modulating endoplasmic reticulum stress in the treatment of cancer," Medecine/Sciences, vol. 31, no. 6-7, pp. 667-673, 2015.

[7] E. Chevet, C. Hetz, and A. Samali, "Endoplasmic reticulum stress-activated cell reprogramming in oncogenesis," Cancer Discovery, vol. 5, no. 6, pp. 586-597, 2015.

[8] M. Zanetti, J. J. Rodvold, and N. R. Mahadevan, “The evolving paradigm of cell-nonautonomous UPR-based regulation of immunity by cancer cells," Oncogene, vol. 35, no. 3, pp. 269-278, 2016.

[9] J. D. Oliver, H. L. Roderick, D. H. Llewellyn, and S. High, "ERp57 functions as a subunit of specific complexes formed with the ER lectins calreticulin and calnexin," Molecular Biology of the Cell, vol. 10, no. 8, pp. 2573-2582, 1999.

[10] S. S. Shishkin, L. S. Eremina, L. I. Kovalev, and M. A. Kovaleva, "AGR2, ERp57/GRP58, and some other human protein disulfide isomerases," Biochemistry (Moscow), vol. 78, no. 13, pp. 14151430, 2013.

[11] C. M. Leys, S. Nomura, B. J. LaFleur et al., "Expression and prognostic significance of prothymosin- $\alpha$ and ERp57 in human gastric cancer," Surgery, vol. 141, no. 1, pp. 41-50, 2007.

[12] L. Cicchillitti, A. Della Corte, M. Di Michele, M. B. Donati, D. Rotilio, and G. Scambia, "Characterisation of a multimeric protein complex associated with ERp57 within the nucleus in paclitaxel-sensitive and -resistant epithelial ovarian cancer cells: the involvement of specific conformational states of $\beta$-actin," International Journal of Oncology, vol. 37, no. 2, pp. 445-454, 2010.

[13] B. J. Grindel, B. Rohe, S. E. Safford, J. J. Bennett, and M. C. Farach-Carson, "Tumor necrosis factor- $\alpha$ treatment of HepG2 cells mobilizes a cytoplasmic pool of ERp57/1,25D 3-MARRS to the nucleus," Journal of Cellular Biochemistry, vol. 112, no. 9, pp. 2606-2615, 2011.

[14] B. Seliger, R. Stoehr, D. Handke et al., "Association of HLA class i antigen abnormalities with disease progression and early recurrence in prostate cancer," Cancer Immunology, Immunotherapy, vol. 59, no. 4, pp. 529-540, 2010.

[15] C. De Martel, J. Ferlay, S. Franceschi et al., "Global burden of cancers attributable to infections in 2008: a review and synthetic analysis," The Lancet Oncology, vol. 13, no. 6, pp. 607-615, 2012.

[16] T. S. Fung, J. Torres, and D. X. Liu, "The emerging roles of viroporins in ER stress response and autophagy induction during virus infection," Viruses, vol. 7, no. 6, pp. 2834-2857, 2015.

[17] S. A. Lozano-Sepulveda, O. L. Bryan-Marrugo, C. CordovaFletes, M. C. Gutierrez-Ruiz, and A. M. Rivas-Estilla, "Oxidative stress modulation in hepatitis C virus infected cells," World Journal of Hepatology, vol. 7, no. 29, pp. 2880-2889, 2015.

[18] P. Safaie, M. Poongkunran, P. P. Kuang et al., "Intrahepatic distribution of hepatitis B virus antigens in patients with and without hepatocellular carcinoma," World Journal of Gastroenterology, vol. 22, no. 12, pp. 3404-3411, 2016.
[19] M. Wang, N. Qiu, S. Lu et al., "Serum hepatitis B surface antigen is correlated with intrahepatic total HBV DNA and cccDNA in treatment-naïve patients with chronic hepatitis B but not in patients with HBV related hepatocellular carcinoma," Journal of Medical Virology, vol. 85, no. 2, pp. 219-227, 2013.

[20] J. M. Lee, B. K. Jang, Y. J. Lee et al., "Survival outcomes of hepatic resection compared with transarterial chemoembolization or sorafenib for hepatocellular carcinoma with portal vein tumor thrombosis," Clinical and Molecular Hepatology, vol. 22, no. 1, pp. 160-167, 2016.

[21] E. Villa, A. Moles, I. Ferretti et al., "Natural history of inoperable hepatocellular carcinoma: estrogen receptors' status in the tumor is the strongest prognostic factor for survival," Hepatology, vol. 32, no. 2, pp. 233-238, 2000.

[22] J. M. Llovet, A. Burroughs, and J. Bruix, "Hepatocellular carcinoma," Lancet, vol. 362, no. 9399, pp. 1907-1917, 2003.

[23] Y.-Y. Chen, F.-C. Liu, T.-S. Wu, and M.-J. Sheu, "Antrodia cinnamomea Inhibits migration in human hepatocellular carcinoma cells: the role of ERp57 and PGK-1," American Journal of Chinese Medicine, vol. 43, no. 8, pp. 1671-1696, 2015.

[24] S. Chichiarelli, E. Gaucci, A. Ferraro et al., "Role of ERp57 in the signaling and transcriptional activity of STAT3 in a melanoma cell line," Archives of Biochemistry and Biophysics, vol. 494, no. 2, pp. 178-183, 2010.

[25] M. H. Choe, J. W. Min, H. B. Jeon et al., "ERp57 modulates STAT3 activity in radioresistant laryngeal cancer cells and serves as a prognostic marker for laryngeal cancer," Oncotarget, vol. 6, no. 5, pp. 2654-2666, 2015. 


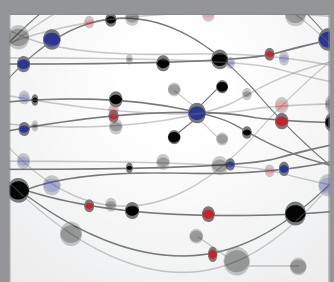

The Scientific World Journal
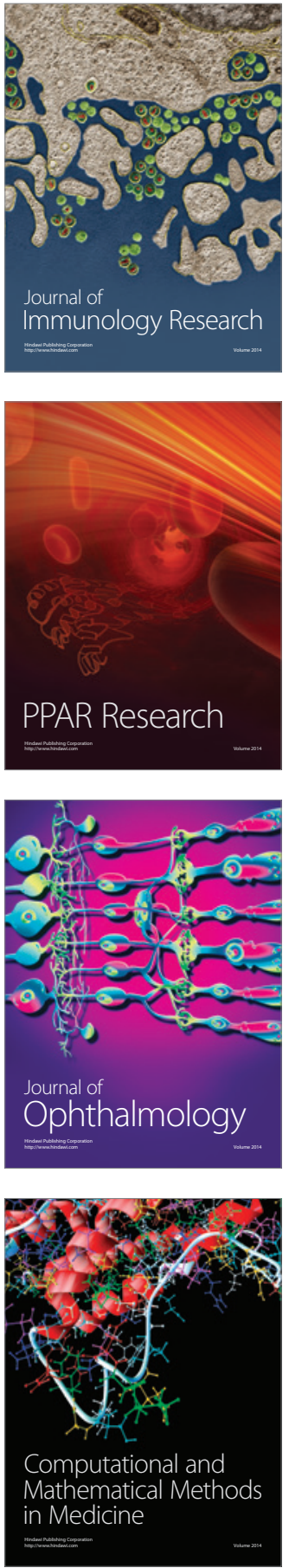

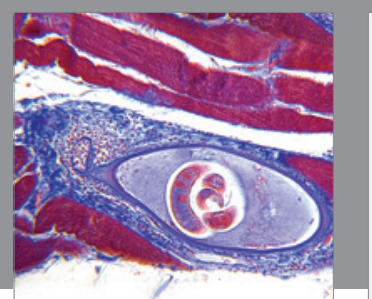

Gastroenterology Research and Practice
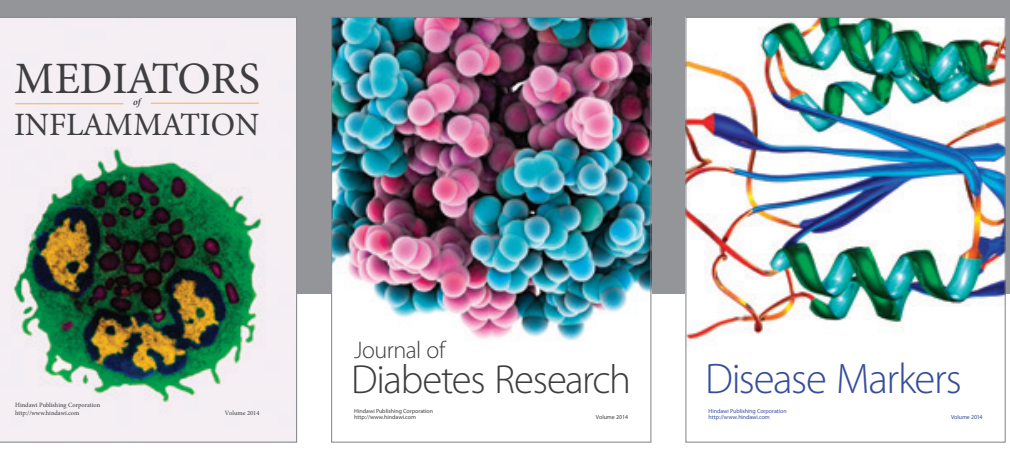

Disease Markers

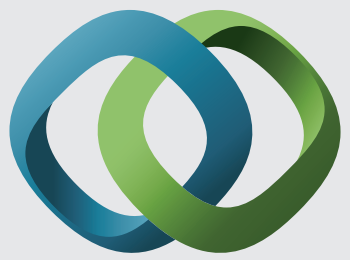

\section{Hindawi}

Submit your manuscripts at

https://www.hindawi.com
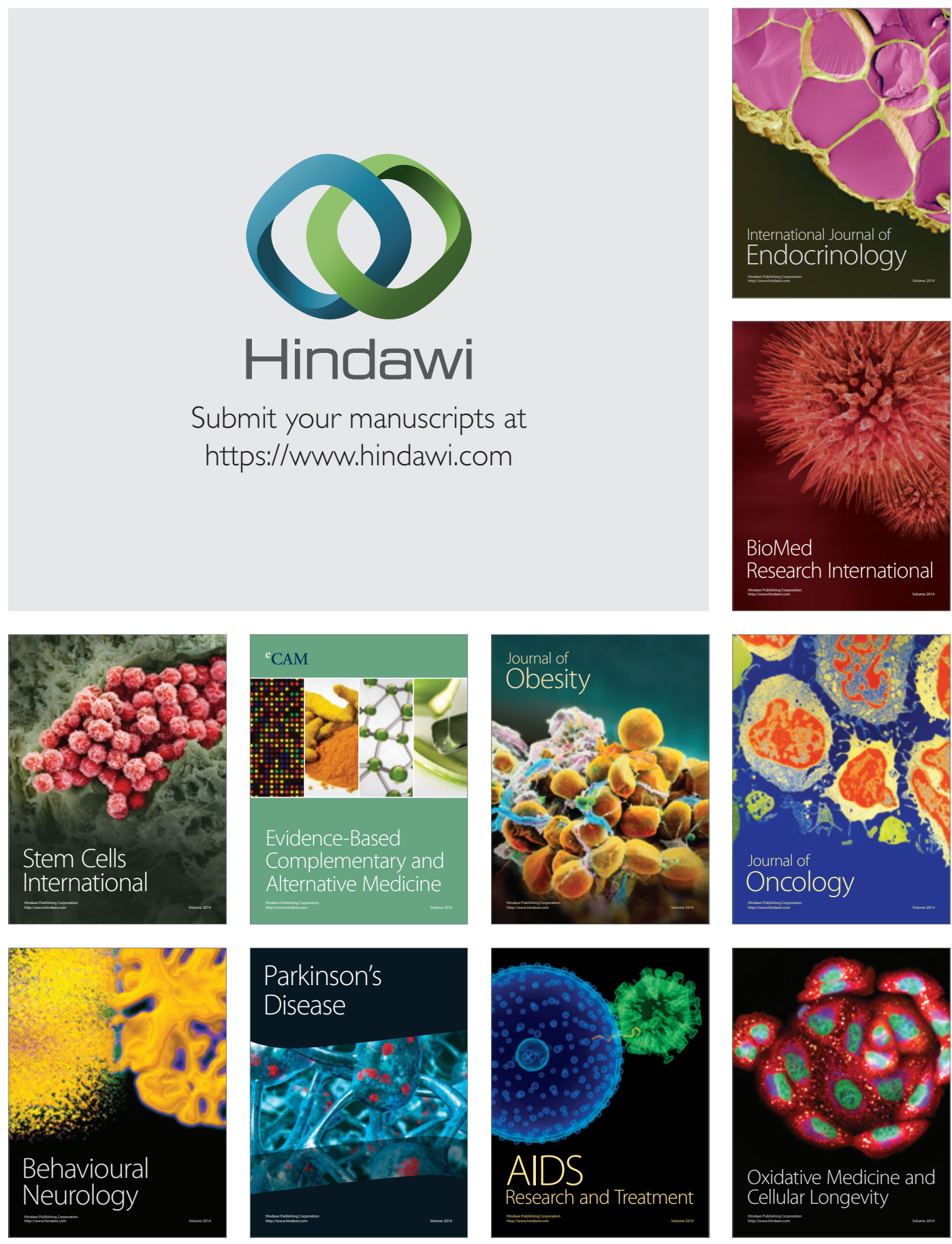